\title{
UM OLHAR ARQUITETÔNICO PARA O AUTISMO: UM ESTUDO DE CASO ANALISANDO AMBIENTES DE TERAPIA SENSORIAL VOLTADOS A CRIANÇAS AUTISTAS
}

\author{
LAUREANO, Claudia de Jesus Braz (1); \\ ZAPATEL, Juan Antônio (2) \\ (1) Universidade Federal de Santa Catarina, Mestre em Arquitetura e Urbanismo \\ e-mail:claubraz@gmail.com \\ (2) Universidade Federal de Santa Catarina, Doutor em Arquitetura e Urbanismo \\ e-mail:project@arq.ufsc.br
}

\begin{abstract}
RESUMO
Este artigo consiste em uma análise nos ambientes de atendimento de terapia sensorial de uma instituição da cidade de Florianópolis - SC, a qual atende crianças com autismo. Esse estudo aborda a possível influência da arquitetura no comportamento humano, apresentando a relação dos espaços de terapia sensorial no comportamento de crianças autistas. Destacam-se alguns conceitos de estudo da área da Psicologia Ambiental e do método de pesquisa chamado Mapa Comportamental. Essa análise possibilitou uma visão eficiente da necessidade de melhora nas condições físicas desses ambientes, indicando quais os elementos ambientais desses espaços possuem possíveis influências no comportamento e desenvolvimento físico-motor de crianças autistas.
\end{abstract}

Palavras chave: autismo; comportamento; arquitetura; terapia sensorial.

\begin{abstract}
This article consists of an analysis in the environments care of sensory therapy about one institution of Florianópolis City - SC, that attend children with autism. This study addresses the possible influence of architecture on human behavior, presenting the relationship of sensory therapy spaces in the behavior of autistic children. Some concepts of the study of Environmental Psychology and the Behavior Map analysis method are highlighted. This analysis allowed an efficient view of the need for improvement in the physical conditions of the study environments, indicating which environmental elements of these spaces have possible influences on the behavior and motor-physical development of autistic children.
\end{abstract}

Keywords: autism; behavior; architecture; sensory therapy.

\section{INTRODUÇÃO}

O ser humano apresenta comportamentos a partir de seus relacionamentos, sejam eles com indivíduos ou com o espaço físico. Esse comportamento pode sofrer influências dos elementos constituintes dos ambientes, principalmente aqueles voltados às atividades que envolvem os estímulos e as perspectivas de seus usuários, como por exemplo os ambientes de terapia sensorial. 


\section{$\dddot{\pi}^{\text {eneac }}$}

As sensações e percepções do ser humano estão diretamente relacionadas ao ambiente que o envolve. Segundo Lombardo (1987), as primeiras evidências sobre o conceito de percepção provêm de Gibson (1966), o qual propõe que a mesma deve ser entendida em termos de sistemas de percepção, detectadas a partir da informação do estímulo, o qual é "acendido" quando o observador ativo se move através do ambiente.

Se analisarmos o indivíduo com autismo, podemos destacar duas características em seu comportamento; limitação nas relações sociais e possível indiferença ou excesso de atenção aos estímulos ao seu redor. Nesse contexto, a criança autista se apresenta como um importante exemplo no estudo das relações da percepção ambiental, pois sua visão espacial e sua relação com o meio sugerem que o ambiente é capaz de gerar informação e/ou sensação que possa interferir em seu comportamento.

Esse estudo irá avaliar alguns ambientes que auxiliam no atendimento de terapias sensoriais voltados às crianças com autismo, analisando os elementos ambientais que compõem esses espaços a partir de um olhar arquitetônico e sob os conceitos de estudos da área da Psicologia Ambiental.

Será apresentado um estudo de caso realizado na Associação de Pais e Amigos de Autistas (AMA- Florianópolis/SC). Esse estudo será pautado pelo levantamento das informações dos ambientes e da análise do comportamento dos usuários dentro dos espaços em uso, a partir do Mapa Comportamental, um instrumento que serve para registrar dados coletados do ambiente construído, em uso, a partir do comportamento dos usuários.

Os resultados encontrados na análise corroboram com a expectativa inicial da necessidade de uma melhora em alguns elementos arquitetônicos nos ambientes em estudo. Bins Ely (2003) considera importante conhecer os elementos do ambiente que podem causar os estímulos sensoriais - perceber e receber informações - e provocar respostas ao nível do corpo - o comportamento. Assim, é possível observar a importância da arquitetura na implementação e planejamento dos espaços, pois esses interferem nas ações, sensações e comportamento de seus usuários.

\section{FUNDAMENTAÇÃO TEÓRICA}

\subsection{Conceitos sobre o autismo}

Autismo é uma palavra de origem grega (autós), que significa por si mesmo. Segundo Orrú (2007) este termo é utilizado na psiquiatria para denominar comportamentos humanos que se centralizam em si mesmos, voltados para o próprio indivíduo.

A ausência de uma causa concreta e a demonstração de diversos aspectos físicos e psíquicos que englobam o autismo, desde a década de 40, a qual são registrados os primeiros estudos a respeito da síndrome, contribuiu para uma compreensão do porquê, durante tanto tempo, foi uma doença "invisível". A falta de clareza nos diagnósticos levou-se sempre ao conceito de esquizofrenia, psicose infantil, entre outros distúrbios (GRINKER, 2010).

Hoje o autismo é descrito como Transtorno do Espectro Autista - TEA, que engloba Transtorno Autista, Transtorno de Asperger e Transtornos Invasivos do Desenvolvimento sem outra especificação, documentado no DSM-5 - Manual Diagnóstico e Estatístico de Transtornos Mentais. Bosa (2001) apresenta além do DSM outro sistema de diagnóstico que classifica o autismo dentro dos conceitos dos transtornos mentais e de comportamento, 0 CID - Código Internacional de Doenças.

De acordo com o DSM-5, o autismo apresenta duas principais características para o diagnóstico: comunicação / interação e comportamento. Araújo (2012) também cita 


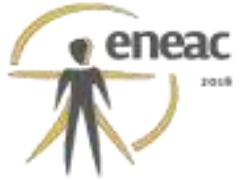

outros fatores importantes reconhecidos no diagnóstico do autismo, que são as alterações sensoriais.

As manifestações características da síndrome variam imensamente, dependendo do nível de desenvolvimento e da idade cronológica do indivíduo, ou seja, não é um diagnóstico padrão, podendo variar os sintomas e suas intensidades de um indivíduo para outro. Segundo a Sociedade Americana de Autismo (ASA, 2015), os comportamentos característicos do TEA podem ser aparentes já nos primeiros meses de idade (entre 18 e 24 meses), mas geralmente tornam-se mais evidentes durante a primeira infância (entre os 24 meses a 6 anos).

\subsection{Psicologia Ambiental e Comportamento}

A Psicologia Ambiental apresenta-se como a relação dos fatores e elementos ambientais influenciando nos sentidos, na percepção e nas ações dos indivíduos diante de um determinado ambiente. De acordo com Bassani (2004), a partir da década de 70, o termo Psicologia Ambiental é utilizado com o intuito de analisar a conexão entre os ambientes físicos, os problemas ambientais e os seres humanos. Nos anos 90 o interesse dessa vertente passa a ser a interação das pessoas com o ambiente sócio-físico (BOMFIM, 2010).

Os elementos espaciais possuem a capacidade de interagir e interferir no comportamento humano a partir da compreensão desse espaço feita pelo usuário. No caso da criança autista, que possui uma capacidade de perceber o ambiente de uma forma diferente de uma pessoa que não tem autismo, esses elementos espaciais podem apresentar um significado particular aos seus sentidos.

De acordo com Bins Ely (1997), o comportamento possui dois níveis: o subjetivo e o objetivo. No nível subjetivo, o comportamento está relacionado ao significado do ambiente, é influenciado por fatores interpessoais e depende dos padrões culturais e das regras sociais. Já no nível objetivo, o comportamento está relacionado às condições de conforto, influenciado pelas qualidades ambientais que favorecem a realização das atividades.

O comportamento da criança autista é considerado o primeiro sinal para um diagnóstico precoce, geralmente percebido pelos pais. Déficits no comportamento social, que acarretam disfunções na comunicação, são os primeiros indícios para a investigação do TEATranstorno do Espectro Autista. Muitas vezes a criança autista não age de forma planejada, antecipando suas ações, pois não consegue conter seus impulsos corporais e neurológicos, com isso, o planejamento de um espaço, promovido por profissionais habilitados, pode contribuir para a percepção e comportamento dos seus usuários. Os movimentos, os percursos feitos nos ambientes, além do uso e apropriação dos elementos constituintes, em geral devem estar integrados com o ambiente para promover ao homem conforto, segurança e funcionalidade. (LAUREANO, 2017, p. 52).

\subsection{Elementos Ambientais Vinculados à Percepção}

Para Penna (1982) a percepção é um processo constante de readaptação, um equilíbrio entre o indivíduo e a informação sobre o meio que o envolve. O autor ainda destaca que perceber é conhecer, e com base nos dados recolhidos, promover-se à coordenação da conduta, ou seja, a partir da percepção tem-se uma ação.

Através da construção do conhecimento do meio é que o ser humano inicia o processo para reconhecer o seu corpo dentro do espaço. O corpo participa ativamente na adaptação e apropriação dos elementos espaciais. Por isso, a compreensão de "mundo" para uma 


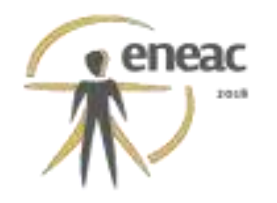

criança com autismo pode se apresentar de forma fragmentada e ou sobrecarregada para seus sentidos, já que sua percepção sensorial é mais apurada do que para as pessoas sem autismo.

Ornstein et.al. (1995) afirma que a relação ambiente e comportamento humano é biunívoca, ou seja, um afeta o outro, e ela está sempre presente, variando somente os níveis de intensidade, destacando quatro categorias que podem apresentar essa inter-relação:

\section{Figura 1 - Elementos ambientais afetando o comportamento}

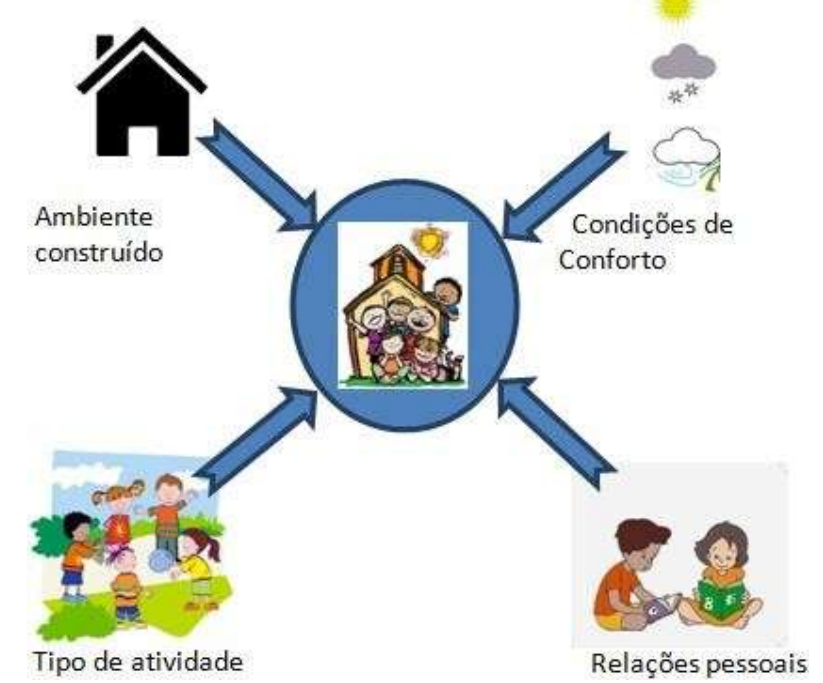

Fonte: Autores (2015), com base em Ornstein et al. (1995, p. 56)

- Ambiente construído: abrange as relações biunívocas entre o comportamento e o espaço (projeto, construção, uso e operação).

- Condições de conforto: envolve as relações biunívocas entre o conforto ambiental e a resposta do comportamento a essas condições.

- Tipo de trabalho (ou atividade): abrange as relações entre o comportamento e as atividades desenvolvidas naquele ambiente

- Relações pessoais: referem-se às relações entre o ambiente construído e as relações entre os indivíduos ali inseridos.

Os elementos constituintes do ambiente são percebidos e apreendidos através do sistema sensorial humano. Os aspectos construtivos de concepção, uso e operação de um espaço estão ligados à sua forma, cor, luz, materiais utilizados, layout, etc. Eles estão diretamente ligados aos conceitos de conforto, funcionalidade e bem-estar dos usuários, provocando sensações e afetando, portanto, o comportamento e as ações desses indivíduos (LAUREANO, 2017).

\section{MÉTODOS}

A seguir serão apresentados os métodos utilizados nesse estudo, descrevendo seus conceitos e importância na realização da pesquisa. 


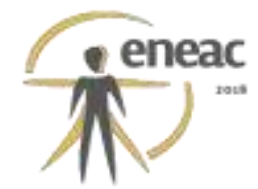

\subsection{Revisão bibliográfica}

A Revisão bibliográfica desse estudo abrange duas vertentes. A primeira é a Pesquisa bibliográfica, que auxiliou o aporte teórico para o presente artigo balizando-o nos conceitos de estudo sobre Psicologia Ambiental (Comportamento e Percepção) e Autismo. A segunda é a Pesquisa documental, a qual consiste na coleta de dados de documentos em arquivos públicos ou privados. Para esse estudo, foram utilizados informações e documentos cedidos por responsáveis técnicos e profissionais da instituição como quadros de horários e informações gerais sobre os atendimentos às crianças.

\subsection{Estudo de Caso}

De acordo com Yin (2001), o estudo de caso se define como "[...] uma investigação empírica que investiga um fenômeno contemporâneo dentro do seu contexto da vida real'. O objetivo desse método visa observar e compreender um evento, descrever fatos ou situações propondo conhecimento sobre o fenômeno estudado, apresentando casos reais. A partir desse conceito, esta pesquisa apresenta um estudo de caso em uma instituição, que possui dois espaços de atendimento terapêutico e sensorial voltados a crianças com autismo.

A AMA - Associação de Pais e Amigos de Autistas, é uma associação criada por um grupo de mães de autistas que necessitavam de um atendimento mais específico aos seus filhos. Hoje ela se localiza em uma edificação adaptada com mobiliários e equipamentos providos através de doações:

Figura 2 - Planta baixa e imagens AMA
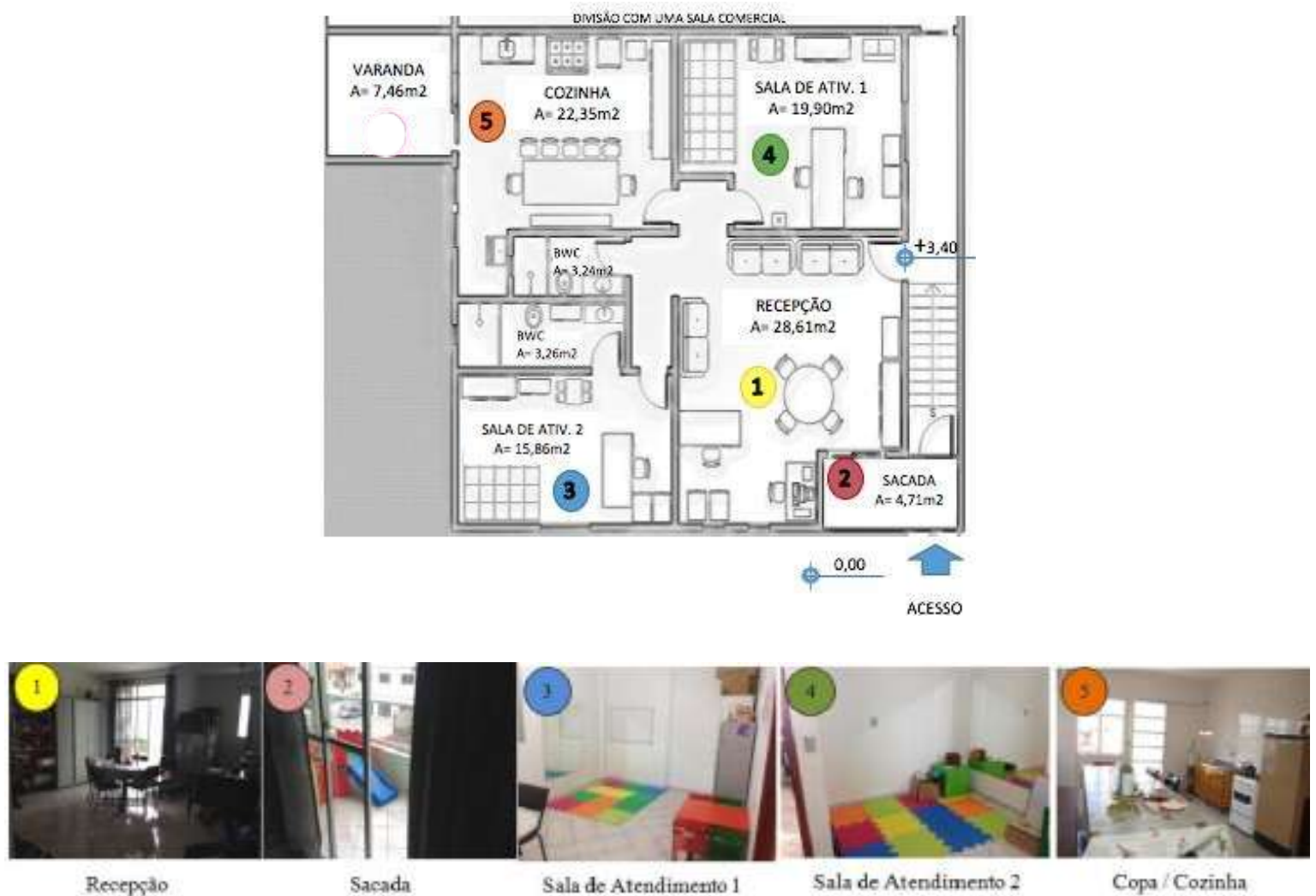

Fonte: Autores, 2015 


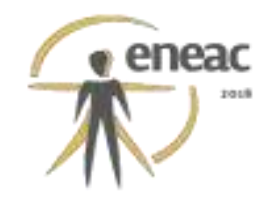

Os ambientes internos estão dispostos da seguinte forma:

- Uma recepção, que também serve como sala de reunião para o atendimento de pais e familiares;

- Uma cozinha, que serve de apoio para o dia a dia e também para reuniões comemorativas realizadas na sede, oferecidas aos autistas, familiares e à comunidade em geral;

- A sala de atividades 1, na qual atua tanto o profissional de Fonoaudiologia como o de Psicologia, que trabalham em horários alternados, individualmente, atendendo um autista por sessão;

- A sala de atividades 2, onde atuam os profissionais de Educação Física, Música e Educação Especial. Cada um deles trabalha individualmente com seus alunos, sendo geralmente um autista por sessão;

- Uma pequena sacada, disposta próxima à recepção, com brinquedos para a interação das crianças que aguardam o atendimento;

- Além de dois banheiros, que servem para o atendimento geral dos usuários e uma varanda que é utilizada como depósito de materiais e equipamentos sem uso.

\subsection{Mapa Comportamental}

Adotou-se para esse estudo o método denominado Mapa Comportamental, o qual é descrito por Rheingantz et al. (2009), como um instrumento para registro das observações sobre o comportamento e as atividades dos usuários sobre um determinado ambiente. É empregado por pesquisadores da psicologia ambiental e do desenho urbano para registro de informações relacionadas com o uso e a apropriação do ambiente, além de ser útil para identificar os arranjos espaciais, ou layouts, os fluxos e as relações espaciais observadas. Os dados analisados foram registrados incluindo as fotos dos ambientes e o comportamento dos usuários (seu posicionamento em função da atividade e layout do espaço).

\section{RESULTADOS E DISCUSSÃO}

Essa análise se baseia no levantamento de dados, descritos a partir das análises dos ambientes, apresentando os elementos espaciais e construtivos que compõem os espaços, e também uma análise comportamental, a qual descreve o comportamento dos usuários diante do seu ambiente em uso.

\subsection{Análise dos ambientes}

O primeiro espaço apresentado é a sala de atividades 1. Ela ocupa uma área de 19,90 m2 e tem a função de atendimento geralmente individualizado, na área de psicologia e fonoaudiologia: 


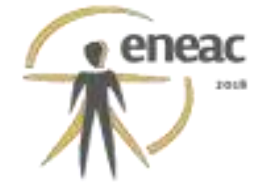

Figura 3 -Características gerais - Sala de Atividades 1

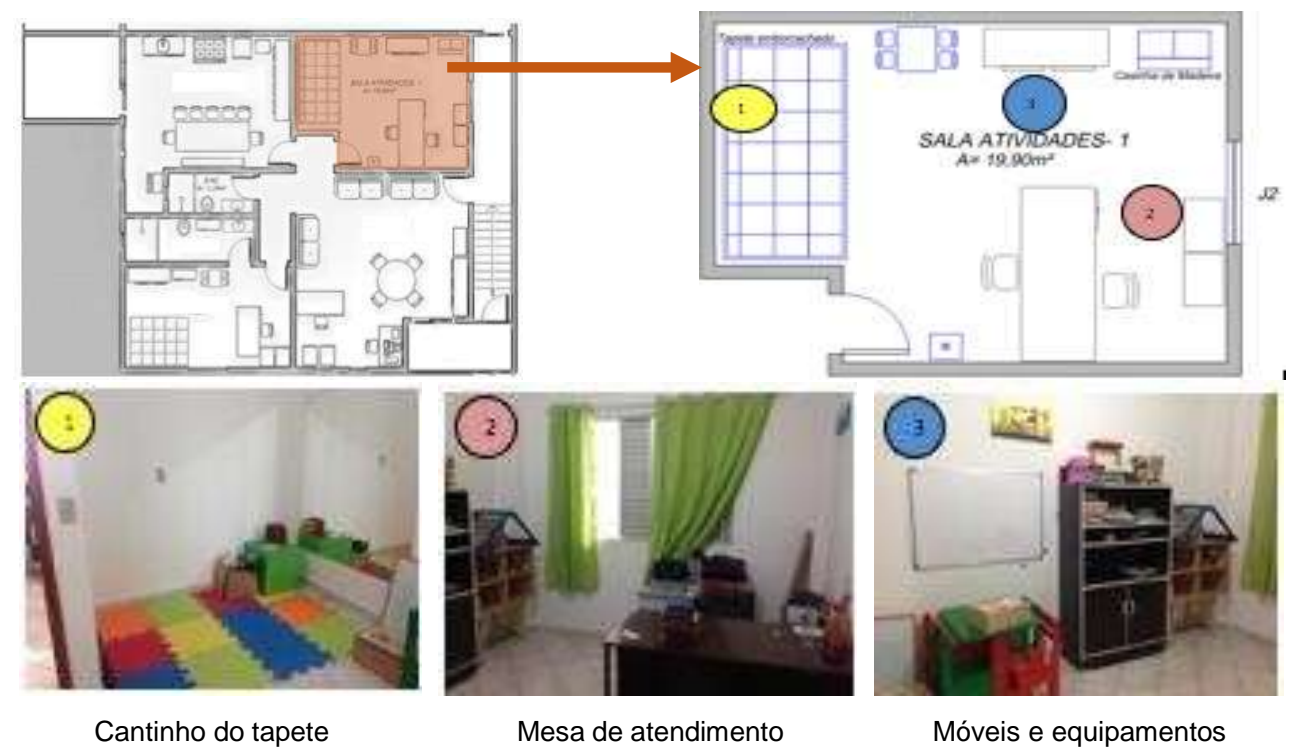

Fonte: Autores, 2016

O próximo ambiente é a Sala de Atividades 2. Possui uma área de 15,86m2, oferecendo atendimento na área de música, educação física e educação especial para os autistas:

Figura 4 - Características gerais - Sala de Atividades 2

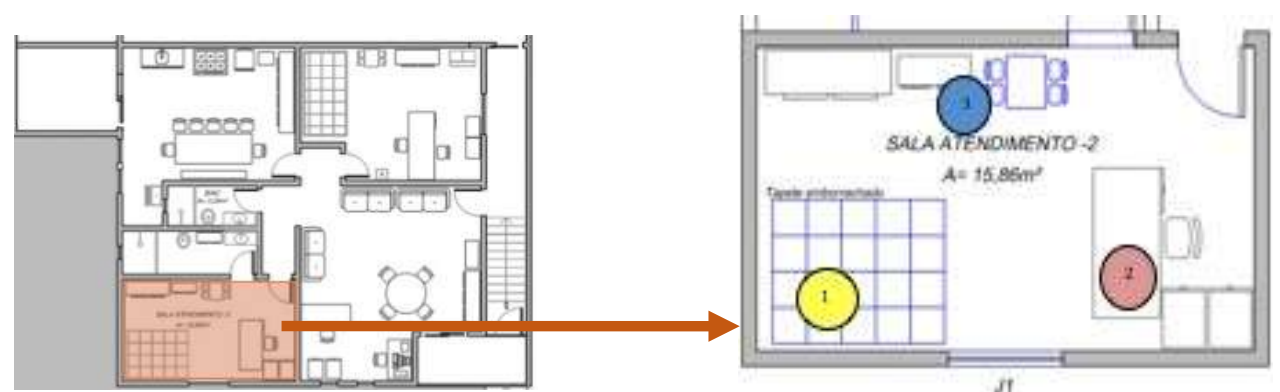

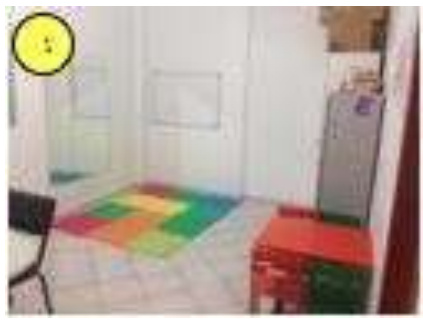

Cantinho do tapete

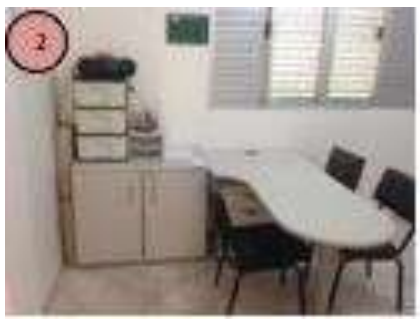

Mesa de atendimento

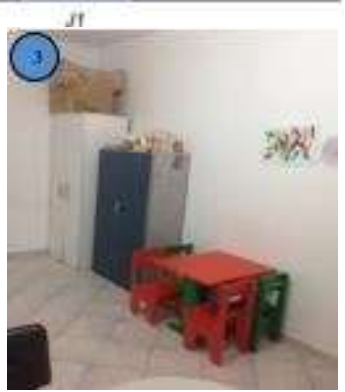

Móveis e equipamentos

Fonte: Autores, 2016

As duas salas possuem elementos construtivos com o mesmo padrão de acabamento. As paredes e teto são de alvenaria pintada de branco. Notam-se muitas superfícies claras, o que permite grande reflexo da luz, podendo causar certo cansaço e desconforto, lembrando que algumas crianças com autismo podem desenvolver hipersensibilidade visual, conforme características do TEA. 
O piso é revestido com cerâmica, o que pode causar desconforto térmico, podendo também, ser inseguro quanto à absorção de impactos, lembrando que crianças com autismo podem ser agitadas em determinados momentos.

Cada sala possui uma janela com veneziana e estrutura em alumínio e vidro, indicando uma atenção em sua manutenção, pois esse material pode fazer muito barulho quando movimentado, oferecendo um possível incômodo sonoro para as crianças. A janela da sala de atividades 1 possui abertura para o corredor interno da edificação, não permitindo uma ventilação natural direta para o ambiente.

As instalações elétricas são embutidas, utilizando apenas um ponto de luz em cada sala. Observou-se uma lâmpada fluorescente para a iluminação de cada espaço, o que indicou certo desconforto lumínico, pois a luz branca, em apenas um ponto do ambiente, impede 0 controle da intensidade e do foco da iluminação.

Outro item investigado foi a acústica; pois a sala de atividades 1 fica ao lado da entrada e da sala de espera, assim, todo o som desses ambientes é transmitido para a sala de atendimento, podendo prejudicar a atenção e a realização das atividades dos profissionais junto às crianças. Já a sala de atividades 2 se localiza na fachada frontal da edificação, a qual fica muito próxima da rua, por onde passam ônibus, caminhões e diversos veículos constantemente, provocando ruídos dentro do ambiente.

O mobiliário e equipamentos presentes nos espaço são basicamente os mesmos: um tapete emborrachado colorido tipo tatame; o qual deve ser observado quanto ao seu tamanho e cores, pois crianças com autismo podem apresentar sensibilidade sensorial para algumas cores intensas em determinados locais; uma mesinha e cadeira infantil em madeira pintada, não apresentou nenhuma observação marcante que pudesse interferir em seu uso; os armários em MDF e acabamento laminado com portas e prateleiras abertas, as quais deixavam expostos certos materiais, o que pode interferir na atenção das crianças em determinadas atividades mais focais; o espelho está fixado diretamente na parede por parafusos (pitons), podendo apresentar uma possível falha quanto a segurança nesse tipo de instalação, pois algumas crianças com TEA são agressivas ou agitadas, e um certo impacto sobre a superfície desse espelho pode causar trincas ou quebra; a mesa de trabalho da profissional da sala 1 é retangular em madeira envernizada, está em bom estado, porém seu tamanho não está adequado ao espaço e ao layout do ambiente, possui cantos retos podendo oferecer insegurança caso alguma criança venha a colidir na mesa, já na sala 2 a mesa de atendimento possui acabamentos arredondados, não oferecendo maior segurança aos usuários; as cadeiras são estofadas em courino, não apresentando desconformidade em seu uso nos espaços analisados.

\subsection{Análise comportamental}

Após conhecer os espaços e suas características construtivas, serão vistas, a seguir, as análises espaciais por outro âmbito, a partir da vivência e da apropriação dos ambientes pelos seus usuários. Nessa análise, o foco será o comportamento humano em seu espaço de uso.

Iniciamos a análise comportamental na sala de atividades 1 , onde ocorre 0 atendimento de uma criança autista de 5 anos de idade e uma psicóloga, com duração média de 40 minutos. A profissional explora o contato físico, visual e afetivo através de diálogos e brincadeiras com a criança: 


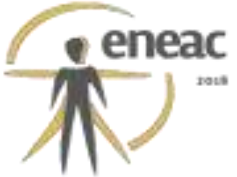

Figura 5 - Registro do comportamento observado - Sala de Atividades 1

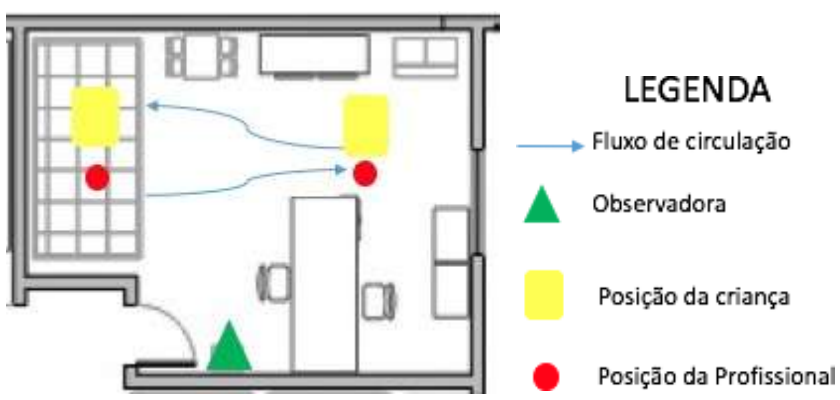

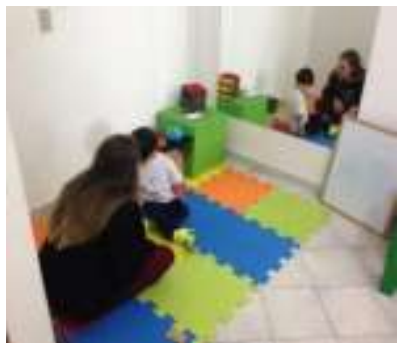

Atividade no tapete

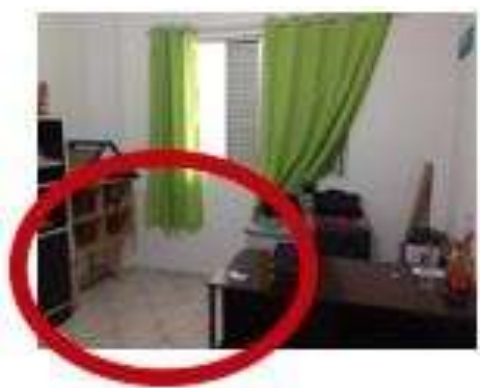

Espaço de circulação do ambiente

Fonte: Autores, 2016

Nesse atendimento a criança entrou na sala e já se dirigiu ao tapete emborrachado, buscando os brinquedos da caixa próxima a ele. Durante quase todo o tempo a psicóloga ficou sentada, mas em um determinado momento a criança buscou uma brincadeira que lhe permitisse se movimentar pela sala. Em um movimento de precaução, a psicóloga colocou as mãos sobre os cantos da mesa para proteger a criança de uma possível colisão.

É possível observar na figura 5, o fluxo de circulação feito pelos usuários no ambiente. 0 layout atual e a utilização de uma mesa de atendimento inadequada ao espaço, não permitem uma apropriação segura do ambiente. Durante o atendimento, foi possível escutar os barulhos externos, nas salas ao redor e fora da edificação. A criança demonstrou uma certa atenção a esses ruídos.

A profissional conseguiu demonstrar certo controle com a atenção da criança durante as atividades, porém por algumas vezes, essa atenção era desviada por conta dos brinquedos que estavam à mostra, nas prateleiras dos armários.

Após o atendimento a profissional se queixou de um pouco de dor de cabeça, podendo ser uma possível consequência do tempo em que ela fica na sala sem uma ventilação e iluminação adequadas. A criança não demonstrou nenhuma alteração ou desconforto no atendimento.

$\mathrm{Na}$ sala de atividades 2, a análise comportamental é feita a partir da observação do atendimento do professor de música e uma criança autista, também com 5 anos de idade. $O$ profissional explora os sons, os movimentos corporais da criança e sua integração com os instrumentos musicais: 


\section{(x) $^{\text {reac }}$}

Figura 6 - Registro do comportamento observado - Sala de Atividades 2
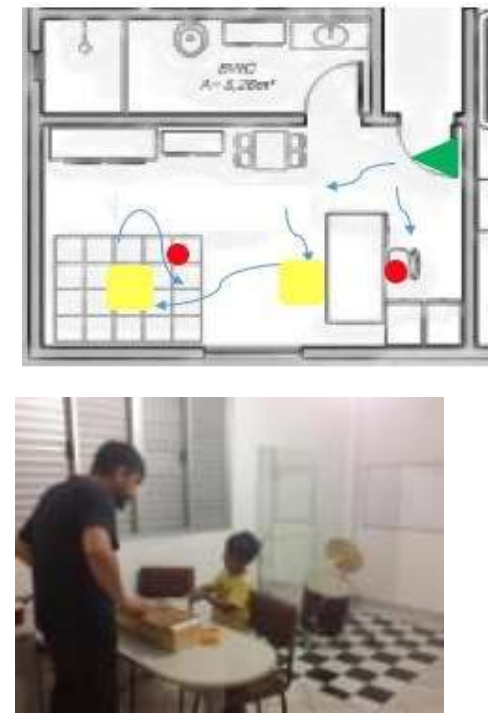

Integração com brinquedo
LEGENDA

$\longrightarrow$ Fluxo de circulaçāo

Observadora

Posição da criança

Posição do Profissional

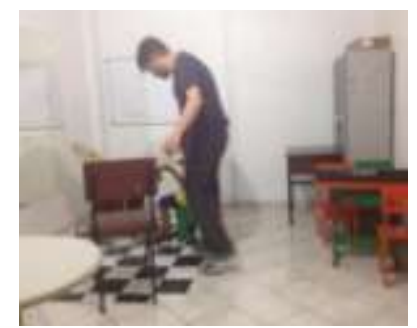

Integração com instrumento musical

Fonte: Autores, 2016

A atividade inicia quando a criança entra na sala e busca um objeto sobre a mesa de trabalho. O professor explora o brinquedo junto com a criança, apresentando algumas peças para ela. Em seguida o profissional leva a criança até a bateria (instrumento musical) montada no canto da sala em frente ao espelho, estimulando os movimentos e a sensibilidade auditiva da criança tocando o instrumento.

A sala estava totalmente fechada, portas e janela. A ventilação que entrava era mínima, apenas pela veneziana de alumínio. Observou-se que a luz branca, no único ponto de iluminação da sala, gerava certo desconforto após algum tempo de permanência no ambiente. O ventilador de teto estava ligado, mas não foi suficiente para melhorar a circulação do ar, além de estar emitindo ruídos, o que pode comprometer a atenção e o interesse das crianças autistas pelas atividades propostas.

A acústica da sala não é adequada para atividades que envolvam instrumentos musicais, pois o uso da bateria, em determinados momentos, com as superfícies lisas e planas, presentes no espaço, ajudam na reverberação dos sons. Isso pode interferir na sensibilidade auditiva das crianças, visando grande probabilidade que os autistas apresentam na hipersensibilidade aos sons do ambiente.

$\mathrm{Na}$ figura 6, é possível observar o fluxo de circulação dos usuários no espaço, demonstrando que a criança tende a explorar o ambiente conforme seu interesse em determinados objetos.

\section{CONCLUSÃO}

De maneira geral, o estudo apresentado indicou informações relevantes sobre as questões físicas, técnicas e funcionais dos ambientes e seus elementos constituintes. Essas informações foram importantes para compreender e analisar o comportamento e a percepção dos usuários nesses espaços em uso, em especial as crianças autistas, que apresentam características específicas de comportamento e interação. 


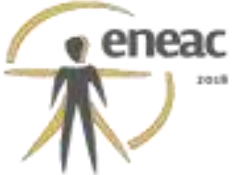

A fundamentação teórica possibilitou uma breve explanação sobre a relação da arquitetura com o tema autismo, a partir dos conceitos da Psicologia Ambiental, evidenciando como o comportamento de crianças autistas pode ser afetado pelo seu ambiente. Além de indicar algumas características gerais sobre o TEA, uma síndrome que cada vez mais, se mostra presente nos diagnósticos médicos em todo o mundo.

O Mapa Comportamental foi um instrumento de extrema importância para a pesquisa, auxiliando nos registros e na compilação dos dados coletados, a partir do conceito de identificar os arranjos espaciais e suas influências nas relações comportamentais humanas em seu uso.

O presente estudo apontou um problema de ordem social. Em uma pesquisa destinada inicialmente às avaliações físicas de alguns espaços, foi observada a necessidade e a importância no planejamento e na elaboração desses ambientes que recebem e acolhem crianças com autismo.

É importante ressaltar que o papel da AMA - Florianópolis é acolher crianças, jovens e adultos autistas e suas famílias, oferecendo um aporte físico e emocional na caminhada do conhecimento e aceitação do TEA. Porém, a associação se mantém com muitas dificuldades operacionais, as quais impedem o crescimento e a melhora em seu espaço físico. Portanto, o intuito desse estudo foi indicar possíveis problemas arquitetônicos e construtivos, no âmbito de planejamento, projeto e execução, auxiliando os profissionais da área para novas implementações, solucionando alguns aspectos que carecem de melhorias ou possam ser evitados.

O ambiente oferece aos seus usuários estímulos e sensações definidos pela apreensão e pela relação do indivíduo com o lugar. O ambiente não pode ser visto apenas como um "espaço físico", seja ele construído ou natural. Este possui um papel importante capaz de estimular a imaginação e as expectativas na relação com seus usuários, o qual é indicado através da arquitetura, que se revela mediadora na relação entre o homem e o meio ambiente.

\section{REFERÊNCIAS BIBLIOGRÁFICAS}

ARAUJO, Álvaro Cabral; NETO, Francisco Lotufo. A Nova Classificação Americana Para os Transtornos Mentais - o DSM-5. Revista Brasileira de Terapia Comportamental e Cognitiva, Belo Horizonte, v. 17, n. 1, p. 47-60, 2012.

ASA. Disponível em: http://www.autism-society.org/ . Acesso em 25 de mar. 2015

BASSANI. Marlise A. Psicologia ambiental: contribuições para a educação ambiental. In: HAMMES. Valéria S. (Org.). Educação ambiental para o desenvolvimento sustentável: proposta metodológica de macroeducação. São Paulo: Ed. Globo, 2004, p. 153- 157.

BINS ELY, Vera Helena Moro. Avaliação de fatores determinantes no posicionamento de usuários em abrigos de ônibus a partir do Método da Grade de Atributos. Tese (Doutorado em Engenharia de Produção) - Programa de Pós-Graduação em Engenharia de Produção, Universidade Federal de Santa Catarina, Florianópolis, 1997.

BINS ELY, Vera Helena Moro. Ergonomia + Arquitetura: buscando um melhor desempenho do ambiente físico. Congresso Internacional de Ergonomia e Usabilidade de Interfaces Interação Humano-Tecnologia: Produtos, Programas, Informação, Ambiente Construído e Transporte, 3, 2003, Rio de Janeiro. Anais... Rio de Janeiro: LEUI/PUC- Rio, 2003.

BOMFIM, Zulmira Áurea Cruz. Cidade e Afetividade: estima e construção dos mapas afetivos de Barcelona e São Paulo. Fortaleza: Edições UFC, 2010. 


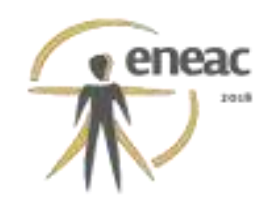

BOSA, Cleonice Alves. As Relações entre Autismo, Comportamento Social e Função Executiva. Psicologia: Reflexão e Crítica, 14(2), Porto Alegre: Universidade Federal do Rio Grande do Sul, p. 281-287, 2001.

GIBSON, J. J. The Senses Considered as Perceptual Systems. Boston: Houghton Mifflin, 1966.

GRINKER, Roy Richard. Autismo: um mundo obscuro e conturbado. São Paulo: Larousse do Brasil, 2010.

LAUREANO, Claudia de J. B. Recomendações Projetuais para ambientes com atendimento de terapia sensorial direcionados a crianças com autismo. Dissertação (mestrado) - Universidade Federal de Santa Catarina, Centro Tecnológico, Programa de Pós-Graduação em Arquitetura e Urbanismo, Florianópolis, 2017.

LOMBARDO, Thomas J. The Reciprocity of Perceiver and Envionmen: the evolution of James J. Gibson's Ecological Psycology. New Jersey: Illinois Department of Mental Health and Developmental Disabilities - College od DuPage, Loyola University, 1987.

ORRÚ, S. E. Autismo, linguagem e educação: interação social no cotidiano escolar. Rio de Janeiro: Wak, 2007.

ORSTEIN, S.; BRUNA, G.; ROMÉRO, M. Ambiente construído \& comportamento: a avaliação pós-ocupação e a qualidade ambiental. São Paulo: Nobel, FAU-USP, 1995.

PENNA, Antonio Gomes. Percepção e Realidade: introdução ao estudo da atividade perceptiva. São Paulo: Mercurio Star, 1982.

RHEINGANTZ, Paulo Afonso; BRASILEIRO, Alice; ALCANTARA, Denise de. Observando a qualidade do lugar: procedimentos para avaliação pós-ocupação. Rio de Janeiro: Universidade Federal do Rio de Janeiro, Faculdade de Arquitetura e Urbanismo, Pós-graduação em Arquitetura, 2009.

YIN, Robert K. Estudo de caso: planejamento e métodos. Porto Alegre: Bookman, 2001. 